\title{
Dieting behaviours, obesity and predictors of dieting among female college students at Palestinian universities
}

W.D. Bayyari, ${ }^{7}$ L.J. Henry ${ }^{7}$ and C. Jones ${ }^{7}$

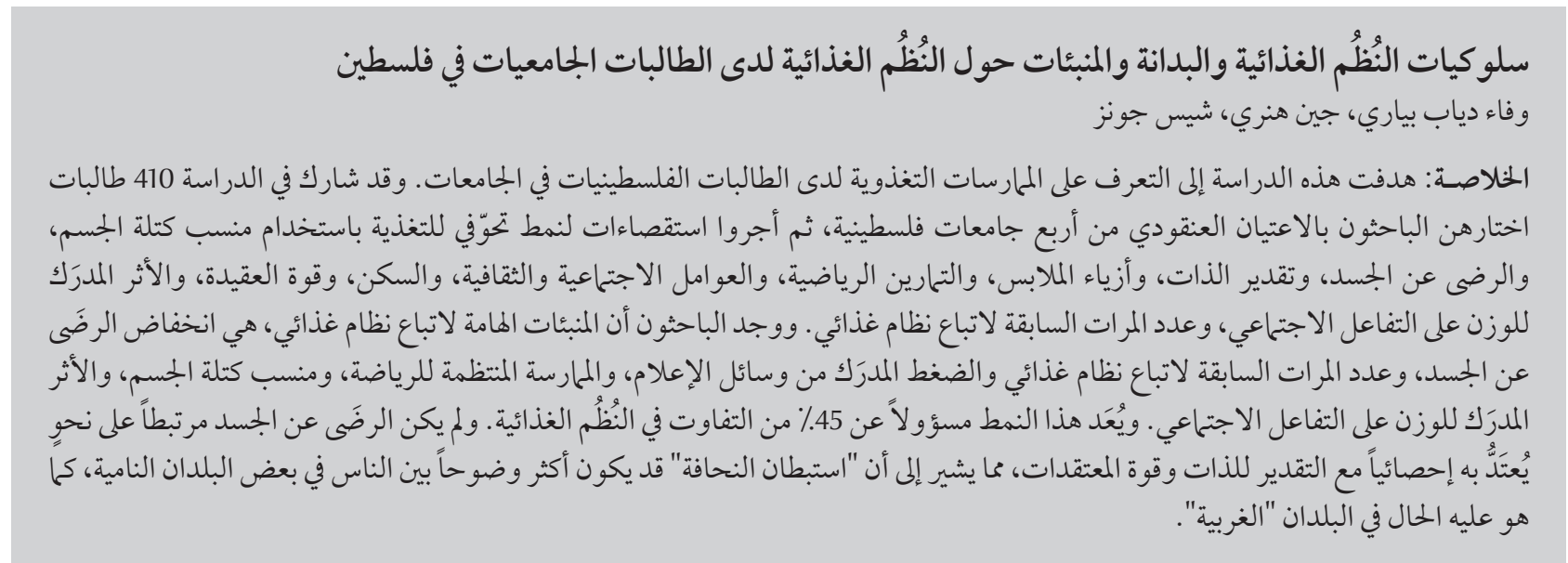

ABSTRACT The purpose of this study was to explore dieting practices of female Palestinian college students. Participants $(n=410)$ were selected by cluster-sampling from 4 Palestinian universities. A regression model investigated dieting using: body mass index (BMI); body satisfaction; self-esteem; dress style; exercise; sociocultural factors; residence; strength of faith; perceived impact of weight on social interaction; and number of previous times dieting. Significant predictors of dieting were low body satisfaction, number of previous dieting times, perceived media pressure, regular exercising, BMI, and perceived impact of weight on social interaction. The model accounted for $45 \%$ of the variance in dieting. Body satisfaction was not significantly correlated with self-esteem or strength of faith, which indicates that "internalization of thinness" may be becoming evident among populations in certain developing countries, as in "Western" countries.

Habitudes alimentaires, obésité et facteurs prédictifs de régimes chez des étudiantes à l'université en Palestine

RÉSUMÉ La présente étude visait à connaître les habitudes alimentaires des étudiantes à l'université en Palestine. Les participantes $(n=410)$ ont été choisies par échantillonnage en grappes dans quatre universités palestiniennes. Un modèle de régression a été utilisé pour étudier leur alimentation en tenant compte des indicateurs suivants : l'indice de masse corporelle, la satisfaction vis-à-vis de son corps, l'estime de soi, le style vestimentaire, l'exercice physique, les facteurs socioculturels, le lieu de résidence, la force de la foi, la perception de l'impact du poids sur les interactions sociales, et le nombre de régimes adoptés auparavant. Les facteurs prédictifs importants pour l'adoption d'un régime étaient une faible satisfaction vis-à-vis de son corps, le nombre de régimes adoptés antérieurement, la perception de la pression des médias, la pratique régulière de l'exercice physique, l'indice de masse corporelle et la perception de l'impact du poids sur les interactions sociales. Le modèle représentait $45 \%$ de la variance pour l'adoption d'un régime. Il n'y avait pas de corrélation significative entre la satisfaction vis-à-vis de son corps et l'estime de soi ou la force de la foi, ce qui indiquerait une possible assimilation de la notion « d'intériorisation de la minceur » dans la population de certains pays en développement, à l'instar des pays occidentaux.

${ }^{'}$ Department of Health Science, Kinesiology, Recreation, and Dance, University of Arkansas, Fayetteville, Arkansas, United States of America (Correspondence to W.D. Bayyari: wafadiab22@hotmail.com).

Received: 14/09/11; accepted: 16/10/11 


\section{Introduction}

Most countries in the Middle East are becoming part of the global obesity pandemic, and the problem becomes significant when the trend towards a more "Western" lifestyle is considered in developing countries. This "Westernization" can put the populations of those countries at a higher risk of obesity and metabolic syndrome than the populations of European and North American countries [1]. Sociocultural pressures to be thin via the media are strong [2], and perceptions of weight appropriateness have been found to be an important component of eating and weight loss behaviours [3]. Dieting is often linked to high body weight and low body satisfaction, thus those who consider themselves overweight and are dissatisfied with their bodies are more likely to diet than those with normal body weight $[4,5]$.

While the issue of dieting and body satisfaction has been deeply investigated in the Western countries, Arab and Muslim populations have rarely been investigated for their dieting behaviours, perceptions of body image, or body satisfaction. Haddad and Moore reported that Muslim women who chose to dress "Islamically" commonly felt free of Western views of women as sex objects [6]. Among Australian Muslim women, strength of religious faith was inversely related to body satisfaction, body selfobjectification, and dietary restraint [7]. These relations were mediated by increased use of modest clothing and by reduced media consumption. Other studies showed evidence of internalization of the "thin ideal" and evidence of the presence of eating disorders among Muslim women indicating that this population was not immune against such medical conditions $[8,9]$.

Some studies have noted that increased exposure to the Western picture of desired thinness through the Internet and the media, along with other sociocultural changes, encourages women to adopt unhealthy dieting behaviours, the most serious of which are anorexia nervosa and bulimia nervosa $[10,11]$.

The aim of this study was to explore dieting practices of female Palestinian college students, and to report rates of obesity and overweight among this population.

\section{Methods}

\section{Procedure}

This study was carried out between May and October 2010. Institutional review board approval was obtained from the University of Arkansas. All participants gave their consent to complete the survey, which consisted of 2 parts: demographics and measures used as predictors for dieting behaviours. The dependent variable was frequency of different dieting practices. Independent variables were: body satisfaction, body mass index (BMI), perceived media pressure, perceived family pressure, perceived pressure from friends, perceptions of the impact of body weight on social interactions, self-esteem, dress style, residence (urban, rural, refugee camp), number of previous times dieting, and strength of faith.

Dieting was assessed using 17 questions related to dieting behaviours practised by the participants within the previous 6 months. The questions were based on the Weight Control Behaviour Scale [12].

Body satisfaction was assessed using pictorial BMI-based body-size guides (http://www.hsc.wvu.edu/ som/hrc/pdfs/IJO\%20Final.pdf) [13]. Participants were asked to choose the picture they thought looked most like their body shape, and then to choose the picture that best represented their desired body shape. The difference between the number of the desired picture and the number of the actual picture can range from -9 to 9 , with negative scores indicating a desire to lose weight, positive scores indicating a desire to gain weight, and a zero score indicating body satisfaction. We used the standard weight status categories for adults: BMI $<18.5=$ underweight, BMI 18.5-24.5 = normal, BMI 25.0-29.9 = overweight, and $\mathrm{BMI} \geq 30=$ obese.

Perceived pressure from media was assessed using a subscale of the Sociocultural Attitudes Towards Appearance Questionnaire 3 [14]. Perceived pressure from family and perceived pressure from friends were assessed using subscales from the Perceived Sociocultural Pressure Scale [15]. This is a 13-item scale related to social interactions of young adults with chronic health conditions [3]. The items assessed the respondents' perceptions of the extent to which their weight negatively influences social interactions.

Self-esteem was measured using the Rosenberg Self-Esteem Scale [16].

Strength of faith was measured using the Santa Clara Strength of Religious Faith Questionnaire [17].

A 2-way analysis of variance test was used to investigate the relationship between body satisfaction and dress style. Body satisfaction was categorized into 3 groups: satisfied, wanted to gain weight, and wanted to lose weight. Dress style was categorized into 3 groups: jilbab (any long and loose-fitting coat or similar garment), modern (dress, skirt, pants) with headscarf, and modern without headscarf.

\section{Participants}

Multiple regression is a large-sample procedure. It is recommended to have 15-30 participants per predictor. We used 12 different variables (including age) as predictors so the estimated sample size would be 360 using the higher value. We used a sample size of 500 to ensure the representativeness of the sample. Using a cluster-sampling technique, 500 female college students, undergraduates from different majors and different college levels, were selected from 4 Palestinian universities 
in the West-Bank only. Due to the political situation and restrictions on movement, we divided the West Bank into 3 geographical areas, north, middle, and south, and we randomly selected 1 university from the north, 2 from the middle, and 1 from the south. Participants were randomly selected from the summer classes offered at each university. The response rate was $85 \%$ $(n=425)$. Data from 15 participants were discarded due to missing data; thus, the study sample consisted of 410 female college students.

\section{Statistics}

Multiple regression analysis was used to investigate the relationship between dieting and other variables. All variables used in the regression model were continuous except for "exercise" and "residence," which were dummy-coded to fit this model.

Data were analysed using SPSS, version 17

\section{Results}

The average age of the 410 participants was 20.01 [standard deviation $(\mathrm{SD})=$ $1.27]$ years.

BMI ranged from 13 to 40 (mean = $21.91, \mathrm{SD}=2.92) \mathrm{km} / \mathrm{m}^{2}$, with the majority being of normal or healthy weight $(77.3 \%, n=317), 8.5 \%(n=35)$ underweight, $12.4 \%(n=51)$ overweight, and only $1.7 \%(n=7)$ obese. Almost 53\% $(n$ $=217)$ reported their residence as urban, $43.4 \%(n=173)$ as rural, and only $3.7 \%(n=15)$ as refugee camp. Dress style was described as jilbab by $39.5 \%$ $(n=162)$ of participants, as modern with headscarf by $42.9 \%(n=176)$, and as modern with no headscarf by $17.6 \%$ $(n=72)$.

The most practised unhealthy dieting behaviour was skipping breakfast: $16.1 \%(n=66)$ reported either often or always practising this behaviour (Table 1). The second most practised unhealthy dieting behaviour was skipping other meals during the day: $10.0 \%$ $(n=41)$ reported often or always practising this behaviour.

The most practised healthy dieting behaviour was increasing the consumption of fruit and vegetables: $47.4 \%(n=$ 194) reported often or always practising this behaviour (Table 1). The second most practised healthy dieting behaviour was increasing exercise: $26.1 \%(n=$ 107) reported often or always practising this behaviour.

When participants were asked to choose the picture that best represented their perceived body shape, $38.3 \%(n=$ 157) chose the second picture, representing normal body weight; $24.4 \%(n=$ 100) chose the third picture, representing normal body weight; and $17.8 \%(n=$ 73) chose the first picture, representing underweight. However, when asked to choose the picture they most desired to look like, $49.0 \%(n=201)$ chose the

\begin{tabular}{|c|c|c|c|c|c|c|c|c|}
\hline \multirow[t]{3}{*}{ Behaviour type } & \multicolumn{8}{|c|}{ Frequency } \\
\hline & \multicolumn{2}{|c|}{ Always } & \multicolumn{2}{|c|}{ Often } & \multicolumn{2}{|c|}{ Sometimes } & \multicolumn{2}{|c|}{ Never } \\
\hline & No. & $\%$ & No. & $\%$ & No. & $\%$ & No. & $\%$ \\
\hline \multicolumn{9}{|l|}{ Healthy dieting } \\
\hline Increase consumption of fruit \& vegetables & 106 & 25.9 & 88 & 21.5 & 104 & 25.4 & 112 & 27.3 \\
\hline Eat less meat & 49 & 12.0 & 51 & 12.4 & 114 & 27.8 & 196 & 47.8 \\
\hline Increase exercise & 43 & 10.5 & 64 & 15.6 & 125 & 30.5 & 178 & 43.4 \\
\hline Use artificial sweeteners & 42 & 10.2 & 59 & 14.4 & 125 & 30.5 & 184 & 44.9 \\
\hline Eat low-calorie foods & 34 & 8.3 & 67 & 16.3 & 114 & 27.8 & 195 & 47.6 \\
\hline Eliminate sweets and junk food & 34 & 8.3 & 61 & 14.9 & 121 & 29.5 & 194 & 47.3 \\
\hline Reduce amount of food at each meal & 33 & 8.0 & 44 & 10.7 & 168 & 41.0 & 165 & 40.2 \\
\hline Eliminate snacking between meals & 29 & 7.1 & 59 & 14.4 & 133 & 32.4 & 189 & 46.1 \\
\hline Eat low-carbohydrate food & 22 & 5.4 & 48 & 11.7 & 132 & 32.2 & 208 & 50.7 \\
\hline Eat or drink low fat food & 20 & 4.9 & 40 & 9.8 & 60 & 14.6 & 290 & 70.7 \\
\hline \multicolumn{9}{|l|}{ Unhealthy dieting } \\
\hline Skip breakfast & 29 & 7.1 & 37 & 9.0 & 71 & 17.3 & 273 & 66.6 \\
\hline Skip other meals to lose weight & 15 & 3.7 & 26 & 6.3 & 85 & 20.7 & 284 & 69.3 \\
\hline Increase smoking & 7 & 1.7 & 3 & 0.7 & 9 & 2.2 & 391 & 95.4 \\
\hline Fast for more than 24 hours & 7 & 1.7 & 12 & 2.9 & 19 & 4.6 & 372 & 90.7 \\
\hline Vomit after eating & 5 & 1.2 & 8 & 2.0 & 27 & 6.6 & 370 & 90.2 \\
\hline Initiate smoking & 4 & 1.0 & 4 & 1.0 & 19 & 4.6 & 383 & 93.4 \\
\hline Use medications ${ }^{\mathrm{a}}$ & 3 & 0.7 & 7 & 1.7 & 25 & 6.1 & 375 & 91.5 \\
\hline
\end{tabular}

${ }^{a}$ Diet pills, laxatives, enemas, diuretics, appetite suppressants. 
second picture, $27.3 \%(n=112)$ chose the first picture, and 20.0\% $(n=82)$ chose the third picture. The majority of the study population $(52.8 \%, n=217)$ wanted to lose weight no matter what their weight category was. Only 17.8\% $(n=73)$ wanted to increase their weight.

Of those participants who described themselves as satisfied with their body weight $(n=120), 6.7 \%(n=8)$ described themselves as underweight, $89.2 \%(n$ $=107)$ as normal, and $4.2 \%(n=5)$ as overweight. Of those who wanted to gain weight $(n=73), 45.2 \%(n=33)$ categorized their body weight as underweight, and $54.8 \%(n=40)$ as normal. Of all those who wanted to lose weight $(n=(217)), 4.1 \%(n=9)$ categorized themselves as underweight, $62.2 \%(n$ $=135)$ as normal, $26.3 \%(n=57)$ as overweight, and 7.4\% $(n=16)$ as obese.

Stepwise regression analysis was conducted to investigate significant predictors of dieting. This analysis involved several multiple regression analyses in which a new predictor was added each time to the prediction model. Correlations among variables and the final prediction model are displayed in Tables 2 and 3. Age was not entered in the regression model. Three predictors were removed from the final regression model: those who were satisfied with their weight $[$ mean difference $(\mathrm{MD})=8.10$, $P<0.05]$, and those who wanted to gain weight $(\mathrm{MD}=9.75, P<0.05)$ (Table 4). There was no statistically significant difference in the means of dieting between those who were satisfied with their weight and those who wanted to gain weight.

\section{Discussion}

Despite an overall low prevalence of overweight and obesity, our findings indicate that participants practised various dieting behaviours, with a tendency towards healthy dieting behaviours. The proportion of women practising healthy dieting behaviours did not match the proportion who were overweight or obese, indicating that healthy dieting was also practised by those who do not actually need to lose weight. Although this could indicate the presence of some warning signs for disordered eating, it may also be an indication that some participants used healthy dieting behaviours to maintain body weight. It may also be that dieting has become the norm among females in developing countries, just as in the more developed countries, where dieting has become a perceived family pressure, perceived pressure from friends, and residence. The results of the regression analysis were statistically significant: $F(6.403)$ $=55.61, P<0.001, R^{2}=0.45$, adjusted $R^{2}=44$, standard error $(S E)=6.24$. The value of $R^{2}$ in this model indicated that the prediction model accounted for $45 \%$ of the variance in dieting behaviour frequency.

The regression analysis showed that differences in the levels of perception about family pressure or pressure from friends to lose weight had no statistically significant impact on dieting. More importantly, there was no statistically significant difference in the dieting behaviours among participants in regard to residence (city, village, refugee camp). Neither self-esteem nor strength of faith had a statistically significant correlation with dieting, thus, both variables were excluded from the prediction model.

There were no statistically significant interactions between dress style and the different levels of body satisfaction. However, there were statistically significant differences in means of dieting among the levels of body satisfaction. There was a statistically significant difference between the means of dieting of those who wanted to lose weight,

\begin{tabular}{|c|c|c|c|c|c|c|c|c|c|c|}
\hline \multirow{2}{*}{ Predictor } & \multicolumn{10}{|c|}{ Predictor } \\
\hline & 1 & 2 & 3 & 4 & 5 & 6 & 7 & 8 & 9 & 10 \\
\hline 1 & 1 & $-0.53^{* *}$ & $0.49^{* *}$ & $0.45^{* *}$ & $0.40^{* *}$ & $0.41^{* *}$ & $0.38^{* *}$ & $0.24^{* *}$ & -0.07 & -0.01 \\
\hline 2 & & 1 & $-0.67^{* *}$ & $.42^{* *}$ & $-.30^{* *}$ & $-.39^{* *}$ & $-.36^{* *}$ & $-.13^{* *}$ & .04 & -0.02 \\
\hline 3 & & & 1 & $0.34^{* *}$ & $0.3^{* *}$ & $0.42^{* *}$ & $0.39^{* *}$ & $0.12^{*}$ & -0.06 & -0.03 \\
\hline 4 & & & & 1 & $0.17^{* *}$ & $0.27^{* *}$ & $0.18^{* *}$ & 0.07 & -0.02 & $-0.1^{*}$ \\
\hline 5 & & & & & 1 & $0.50^{* *}$ & $0.45^{* *}$ & $0.23^{* *}$ & $-0.12^{*}$ & -0.08 \\
\hline 6 & & & & & & 1 & $0.75^{* *}$ & $0.28^{* *}$ & -0.06 & -0.07 \\
\hline 7 & & & & & & & 1 & $0.36^{* *}$ & $-0.15^{* *}$ & -0.09 \\
\hline 8 & & & & & & & & 1 & $-0.23^{* *}$ & -0.01 \\
\hline 9 & & & & & & & & & 1 & 0.09 \\
\hline 10 & & & & & & & & & & 1 \\
\hline
\end{tabular}

1 = dieting behaviours, 2 = body satisfaction, 3 = body mass index, $4=$ previous dieting attempts, $5=$ pressure from media, $6=$ family pressure, $7=$ pressure from friends, $8=$ perceived impact of weight on social interaction, $9=$ self-esteem, $10=$ strength offaith .

${ }^{*}$ Correlation significant at 0.05 level (2-tailed).

${ }^{* *}$ Correlation significant at 0.01 level (2-tailed). 


\begin{tabular}{|c|c|c|c|c|c|c|}
\hline Predictor & B & SE B & $\beta$ & $t$ & $s r^{2}$ & $R^{2}$ \\
\hline Model & & & & & & 0.45 \\
\hline Constant & -9.60 & 3.06 & & $-3.14^{* *}$ & & \\
\hline Body satisfaction & -1.41 & 0.32 & -0.23 & $-4.36^{* * *}$ & 0.28 & \\
\hline Previous dieting & 0.73 & 0.13 & 0.24 & $5.69^{* * *}$ & 0.06 & \\
\hline Media pressure & 0.25 & 0.05 & 0.20 & $5.80^{* * *}$ & 0.06 & \\
\hline Exercise & 2.64 & 0.63 & 0.16 & $4.21^{* * *}$ & 0.02 & \\
\hline Body mass index & 0.49 & 0.14 & 0.15 & $3.42^{* *}$ & 0.02 & \\
\hline Social pressure & 0.11 & 0.04 & 0.11 & $2.98^{*}$ & 0.01 & \\
\hline
\end{tabular}

${ }^{*} P<0.05,{ }^{* *} P<0.01,{ }^{* * *} P<0.001$.

$S E=$ standard error.

way of life, and that a large proportion of women have dieted at some point in their lives, as seen in other studies $[18,19]$.

In this study, the most practised unhealthy dieting behaviour was skipping meals, particularly breakfast; the prevalence of other unhealthy dieting behaviours was very low. Despite the fact that identification of these behaviours alone was not intended to identify disordered eating or eating disorders, it might raise concern about the probability of a clinical or subclinical diagnosis of such conditions. These findings are consistent with the results of other studies reporting such practices among female college students [20-22].

Our study population showed body dissatisfaction in 2 directions: those who wanted to gain weight, and those who wanted to lose weight. Other studies have reported that even females who are not overweight or obese still desire to be thinner [23]. In our study, only
$14 \%$ were overweight or obese, yet 53\% wanted to lose weight, which might reflect low body satisfaction. Almost $4 \%$ of those who wanted to lose weight identified their body weight as underweight, and $62 \%$ as normal, which indicates that the internalization of thinness is evident among this population, and that the desire to lose weight is not necessarily correlated with high body weight.

Our results indicate that body dissatisfaction, rather than actual BMI, is a better predictor of dieting. The number of previous dieting attempts and the significant correlation with current dieting indicated that those who had previously engaged in dieting, mainly during adolescence, were more likely to continue practising some dieting behaviours as young adults.

Sociocultural factors have been explored by researchers in regard to their influence on women's dieting behaviours. As might be expected, perceived media pressure was a significant predictor of dieting. In a previous study, perceived media pressure to be thin was correlated with increased weight and body dissatisfaction, and this experience of pressure involved exposure to, and internalization of, the slender ideal, which in turn increased the probability of various eating and emotional problems [24].

Perceived family pressure to lose weight did not emerge as a significant predictor of dieting. One explanation for this is that most previous studies have been conducted among adolescent females, so there is a probability that, because our study population was older, perceived family pressure was lower, or participants may not have provided an accurate evaluation of such pressure. Perceived family pressure might also be confused with pressure from the media or the community, so participants might not be aware of it. Another possible explanation is that participants might purposely deny any

\begin{tabular}{|c|c|c|c|c|c|}
\hline Source & df & SS & MS & $\boldsymbol{F}$ & $R^{2}$ \\
\hline Dress style (A) & 2 & 119.43 & 59.71 & 1.15 & 0.00 \\
\hline Body satisfaction (B) & 2 & 6729.20 & 3364.60 & $64.97^{* * *}$ & 0.23 \\
\hline$A^{*} B$ interaction & 4 & 123.43 & 30.87 & 0.60 & 0.00 \\
\hline Within groups & 401 & 20766.92 & 51.79 & & \\
\hline Total & 409 & 28663.65 & & & \\
\hline
\end{tabular}

*** $P<0.001$.

$d f=$ degrees offreedom, $S S=$ sum of squares, $M S=$ mean square. 
such family pressure in order to feel more independent in their college years.

In this study, self-esteem had no significant correlation with dieting, nor was there any significant correlation with body satisfaction or strength of faith. To date, little research has been conducted exploring the relationship between strength of faith and body satisfaction and dieting behaviours. However, outward differences in expression of the Muslim faith (only 9 of our participants were not Muslim), such as dress, would appear to warrant exploration of this factor. In contrast to the findings of Mussap, who found that among Muslim women, strength of faith was inversely related to body dissatisfaction and dietary restraint [7], we found no such relationship between faith and dieting, faith and self-esteem, or faith and body satisfaction. A possible explanation for this contrast may be the difference in the mean age between the 2 Muslim populations: the mean age in Mussap's study was 27.34 years, while the mean age in our study was 20.1 years. Also, the population in Mussap's study was living in Australia, a "Western" environment, while our participants lived in the West Bank, a Muslim environment. This might have affected perceptions of the impact of faith on different aspects of life. Wearing the jilbab (traditional Islamic dress) does not prevent Muslim females from having the desire to diet or to be thinner. With the effects of globalization, the impact of the media on body image is expected to increase, so eating disorders may start to appear among this population. According to 1 study, many media researchers have asserted that observation of Arab society reveals obvious "Western" influence on women and girls with regard to fashion, dress, and fast food consumption [25].

This study had a number of limitations. The sample was not randomly chosen and responses were self-reported, which may raise concerns about generalization of the results. Some of the factors used as predictors for dieting (e.g. media) need to be further investigated for their impact on dieting. Neither the media content, nor the exposure time to media were investigated, therefore, our study does not explain the mechanism by which media impacts dieting, and does not report the degree of "westernization" in the media to which the participants were exposed. Another limitation is that body dissatisfaction was assessed only through body weight or size, so the results related to this particular variable may not be generalized to overall body satisfaction status. The results do not reflect a clinical diagnosis of any eating disorder or disordered eating, but they indicate that this population may not be immune to such conditions. These would need further investigation based on clinical diagnosis to estimate the actual prevalence rates among this population.

Despite these limitations, the study explores dieting in a new population living in a developing country that is undergoing rapid social and economic changes. Perhaps the most important finding is that dieting is a complex process that can be predicted mainly from low body satisfaction, rather than BMI. The internalization of the "Western ideal thin" was evident among this population, no matter what their body weight or dress style. Media was a key factor shaping this internalization and it was significantly correlated with the social pressure that affects the impact of the perception of body weight on social interaction, which in turn may increase the probability of practising dieting behaviours. The role of sociocultural factors such as media should be thoroughly investigated to design evidence-based interventions that increase knowledge and awareness about body weight and body satisfaction.

\section{References}

1. Bahrami $\mathrm{H}$ et al. Obesity and hypertension in an Iranian cohort study; Iranian women experience higher rates of obesity and hypertension than American women. BMC Public Health, 2006, 6:158.

2. Wan W, Faber RJ, Fung A. Perceived impact of thin female models in advertising: A cross-cultural examination of third person perception and its impact on behaviors. Asia Pacific Journal of Marketing and Logistics, 2003, 15(1/2):5173.

3. Gross SM et al. Gender differences in body image and health perceptions among graduating seniors from a historically black college. Journal of the National Medical Association, 2005, 97:1608-1619.

4. Markey CN, Markey PM. Relations between body image and dieting behaviours: an examination of gender differences. Sex Roles, 2005, 53(7-8):519-530.

5. Millstien $\mathrm{R}$ et al. Relationships between body size satisfaction and weight control practices among US adults. Medscape Journal of Medicine, 2008, 10(5):119-129.
6. Haddad Y, Smith J, Moore K. Muslim women in America: the challenges of Islamic identity today. Oxford, Oxford University Press, 2006.

7. Mussap A. Strength of faith and body image in Muslim and non-Muslim women. Mental Health, Religion \& Culture, 2009, 12:121-127.

8. Abdollahi P, Mann T. Eating disorder symptoms and body image concerns in Iran: comparisons between Iranian women in Iran and in America. International Journal of Eating Disorders, 2001, 30:259-268.

9. Ahmad S, Waller G, Verduyn C. Eating attitudes and body satisfaction among Asian and Caucasian adolescents. Journal of Adolescence, 1994, 17(5):461-470.

10. Herman C, Polivy J, Leone T. The psychology of overeating. In: Mela D, ed. Food, Diet, and Obesity. Cambridge, Woodhead Publishing, 2005:115-136.

11. Makino M, Tsuboi K, Dennerstein L. Prevalence of eating disorders: a comparison of Western and non-Western countries. Medscape General Medicine, 2004, 6(3):49. 
12. French $\mathrm{S}$ et al. Dieting behaviours and weight change history in female adolescents. Health Psychology, 1995, 14(6):548555.

13. Harris CV et al. BMI-based body size guides for women and men: development and validation of a novel pictorial method to assess weight-related concepts. International Journal of Obesity, 2008, 32:336-342.

14. Thompson J et al. The sociocultural attitudes towards appearance questionnaire-3(SATAQ-3): development and validation. International Journal of Eating Disorders, 2004, 35:293-304.

15. Stice E, Nemeroff C, Shaw H. A test of dual pathway model of bulimia nervosa: Evidence of restrained eating and affect regulation mechanisms. Journal of Social and Clinical Psychology, 1996, 15:340-363.

16. Rosenberg M. Society and the adolescent self-image. Princeton, Princeton University Press, 1965.

17. Plante $\mathrm{T}$, Boccaccini $\mathrm{M}$. The Santa Clara strength of religious faith questionnaire. Pastoral Psychology, 1997, 45(5):375-387.

18. Packard $P$, Krogstrand KS. Half of rural girls aged 8 to 17 years report weight concerns and dietary changes, with both more prevalent with increased age. Journal of the American Dietetic Association, 2002, 102:672-677.

19. Wadden TA et al. Dissatisfaction with weight and figure in obese girls: discontent but not depression. International Journal of Obesity, 1989, 13:89-97.

20. Malinauskas B et al. Dieting practices, weight perceptions, and body composition: A comparison of normal weight, overweight, and obese college females. Nutrition Journal, 2006, 5:11

21. Soliah L, Walter J, Antosh D. Dieting behaviours of young women post-college graduation. College Student Journal, 2007, 41:1064-1077.

22. Tamim $\mathrm{H}$ et al. Weight control measures among university students in a developing country: a cultural association or a risk behavior. Journal of the American College of Nutrition, 2004, 23:391-396.

23. McCabe MP, Ricciardelli LA. Body image and strategies to lose weight and increase muscle among boys and girls. Health Psychology, 2003, 22(1):39-46.

24. Levine MP, Murnen SK. Everyone knows that mass media are/are not [pick one] a cause of eating disorders: a critical review of evidence for a causal link between media, negative body image, and disordered eating in females. Journal of Social and Clinical Psychology, 2009, 28(1):9-42.

25. Obeidat R. Content and representation of women in the Arab media. Paper presented at the Expert Group Meeting on "Participation and access of women to the media, and the impact of media on, and its use as an instrument for the advancement and empowerment of women", Beirut, Lebanon, 12-15 November 2002. New York, United Nations Division for the Advancement of Women, 2002 (EGM/MEDIA/2002/EP.11) (http://www.un.org/womenwatch/daw/ egm/media2002/reports/EP11Obeidat.PDF, accessed 29 September 2012). 